\title{
The Jubilee's Impetus
}

Die 43. Tagung der Deutschen Dermatologischen Gesellschaft fand vom 20.-23. April 2005 in Dresden statt. Unsere deutschsprachigen Kollegen und viele Freunde und Kollegen aus Europa und weiterher haben uns besucht und zum Gelingen beigetragen. Es haben sich mehr als 2500 Kenner und Könner der Dermatologie versammelt und der Kongress ist bestens gelungen. Ja, wir Dermatologen haben Dresden gefüllt, überfüllt. So kam es zu Überbuchungen von Hotels und unerfreulichen Verschiebungen Betroffener, aber auch zu einem regen Besuch von Dresden als Stadt und als bedeutendes Kulturzentrum. Der Wiederaufbau des einstigen Zentrums verbindet sich mit moderner Urbanität. Fast meint man, die Metropole sei jetzt schon für den erhofften Bevölkerungszuwachs ausgerichtet worden. Besser als umgekehrt! Der Kongress selber erfüllte das neu errichtete internationale Kongresszentrum (ICC) am Elbufer und bot Dichte der Begegnung im Inneren und Weite des Auslaufes auf der raumgekrümmten Terrasse über der Elbe. Das frische und sonnige Frühlingwetter stimulierte beides, die Tagung und den Stadtbummel.

Die Tagung selber hat das Fach selbstbewusst, sicher und stark dargestellt und wir brauchen uns in der Tat nicht zu verstecken. Sowohl die Forschung als auch die Patientenversorgung sind zuverlässig und ideenreich, gut aufgestellt und anerkannt. Der Tagungsleitung ist ein großer Wurf gelungen und wir alle beglückwünschen die Kollegen herzlich.

Für unsere Zeitschrift war der Empfang unseres Georg Thieme Verlags am Donnerstag, dem 21. April 2005 im Rahmen der DDGTagung von besonderer Bedeutung, ist doch bei dieser Gelegenheit uns Jubiläumsband „30 Jahre Aktuelle Dermatologie“ (Abb.1) vorgestellt und ausgegeben worden. Die Herausgeber waren anwesend und der Verlagsleiter Klinik und Praxis, Herr Dr. Udo Schiller, begrüßte die Gäste im Namen des Verlegers Herrn Albrecht Hauff. Mit dieser sehr gelungenen Präsentation des Jubiläumsbandes ist das 30-jährige Jubiläum unserer Zeit-

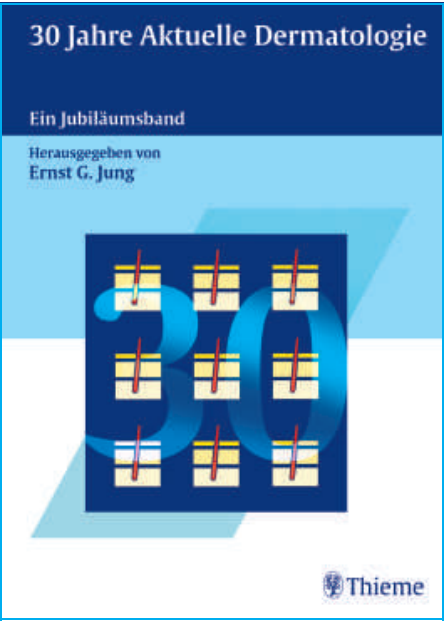

Abb. 1 Titelblatt unseres Jubiläumsbandes 2005 .

schrift erfolgreich vollendet. Es hat sich von 2004, dem 30. Jahr, hinüber in 2005 gezogen und wurde jetzt gekrönt und abgeschlossen - durch den Jubiläumsband. Er gibt besonders Gewicht und Nachhaltigkeit!

Nun stellt sich unsere Zeitschrift mit ihrem Profil in der deutschsprachigen Dermatologie bestens dar. Sie dient dem Transport nationaler und internationaler Forschung und Entwicklung hinein in die patientenorientierte Anwendung im deutschen Sprachraum. Zudem bietet sie unseren Fachärzten das Publikationsorgan für ihrer eigene Forschung und Erfahrung. Sie dient aber auch unseren jungen Fachkollegen, erste Erfahrung in Darstellung und Präsentation eigener Befund und Kasuistiken zu gewinnen. Die Geschichte unseres Faches ist weiter ein Anliegen und auch die Rubrik zur Kulturgeschichte.

Gut gerüstet geht die Zeitschrift „Aktuelle Dermatologie“ aus der Konsolidierung heraus - in eine neue Phase kraftvoller Entwicklung. Dazu bitten wir um die Mitwirkung unserer Leser. 